\title{
Cytokinin activity in Citrus seedlings colonized by mycorrhizal fungi
}

\author{
R.K. Dixon* \\ School of Forestry, Auburn University, Auburn, AL 36849, U.S.A.
}

\section{Introduction}

The level of cytokinin-like substances is greater in the leaves of the vesicular-arbuscular mycorrhizal monocotyledon Bouteloua gracilis compared to nonmycorrhizal plants (Allen et al., 1980). This increase may be associated with colonization of roots by vesicular-arbuscular mycorrhizal fungi or the result of improved mineral nutrition (Van Staden and Davey, 1979). The objectives of this research were to: 1) establish the presence of cytokinins in leaves of Citrus jambhiri Lush. seedlings inoculated with vesicular-arbuscular mycorrhizal fungi; and 2) isolate cytokinins with demonstrated biological activity.

\section{Materials and Methods}

Five vesicular-arbuscular mycorrhizal fungi including Glomus caledonium (Nicol. and Gerd.), G. epigaeum (Dan and Trappe), G. etunicatum (Becker and Gerd.), G. fasciculatum
Thaxt. (Gerd. and Trappe) and G. mosseae (Nichol. and Gerd.) were used to inoculate seedlings using methods described by Bethenfalvay and Yoder (1981). Plants were grown in a glasshouse for $105 \mathrm{~d}$ under previously described culture coriditions (Menge et al., 1978).

Following harvest, seedling dry weight and vesicular-arbuscular mycorrhizal colonization of inoculated and non-inoculated plants were measured. Seedling leaf subsamples were analyzed for phosphorus content (Menge et al., 1978).

Leaf samples were collected for cytokinin analysis before final harvest of seedlings. The partially purified cytokinin extracts of fully expanded leaves were separated by high performance liquid chromatography using procedures described by Horgan and Kramers (1979).

\section{Results}

All C. jambhiri seedlings inoculated with fungal symbionts exhibited abundant vesicular-arbuscular mycorrhizal development after $105 \mathrm{~d}$. Coritrol seedlings were nonmycorrhizal. Inoculation of Citrus seedlings with vesicular-arbuscular mycorrhizal fungi significantly influenced total dry

\footnotetext{
- Present address: Environmental Research Laboratory. U.S. Environmental Protection Agency, 200 SW 35th St., Corvallis, OR 97333 , U.S.A.
} 


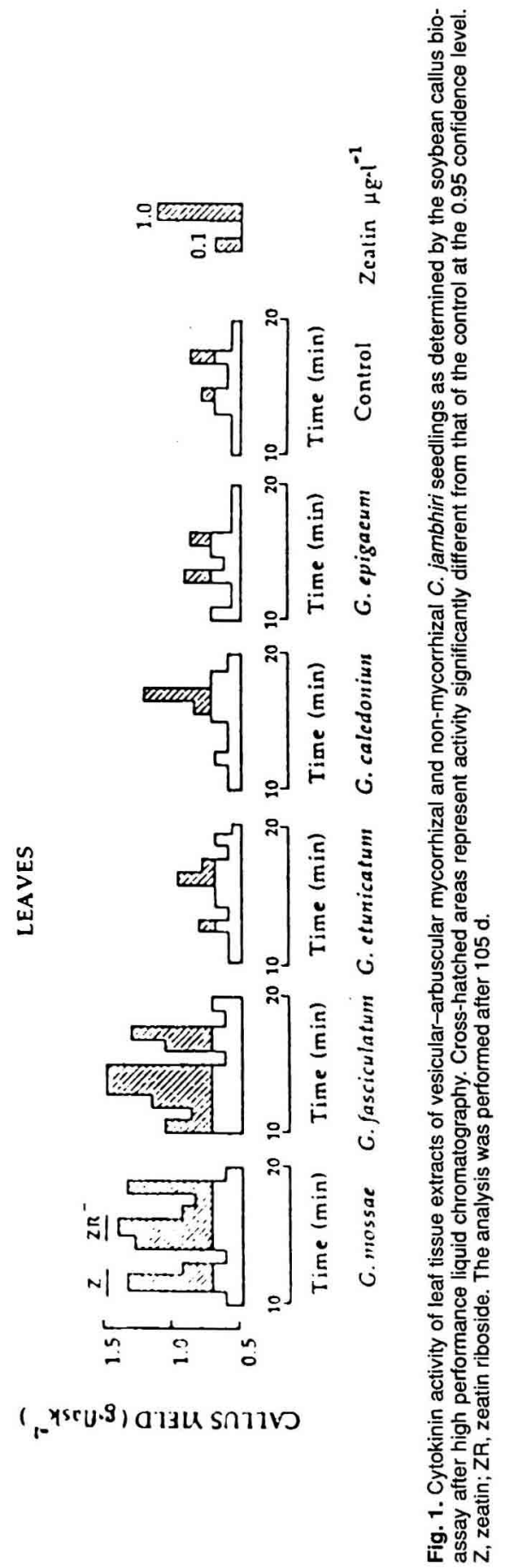

weight and phosphorus content of leaves. Seedlings inoculated with $G$. caledonium, $G$. fasciculatum and $G$. mosseae were significantly larger than the non-inoculated control plants. Similarly, leaf phosphorus levels were significantly greater in the vesicular-arbuscular mycorrhizal seedlings compared to the non-mycorrhizal plants.

Inoculation with vesicular-arbuscular mycorrhizal fungi significantly increased cytokinin activity in leaves of $C$. jambhiri. Colonization by $G$. fasciculatum and $G$. mosseae resulted in a significant increase in seedling leaf cytokinin activity. Several cytokinins, including zeatin and zeatin riboside, were detected in seedling leaves.

\section{Discussion and Conclusion}

These results demonstrate the presence of cytokinins in leaves of $C$. jambhiri. Endogenous cytokinin activity in $C$. jambhiri leaves has not been reported previously. The cytokinin activity in leaves may be attributable to acropetal transport from roots and/or regulation to cytokinin oxidase enzymes (Van Staden and Davey, 1979).

This study established significant changes in cytokinin activity in leaves attributable to colonization of seedlings with different vesicular-arbuscular mycorrhizal symbionts. Changes in cytokinin-like activity in leaves of other Citrus species due to vesicular-arbuscular mycorrhizal colonization was also reported by Edriss et al. (1984). The significantly greater cytokinin activity in the leaves of vesicular-arbuscular mycorrhizal C. jambhiri, relative to nonmycorrhizal seedlings, is consistent with the report of zeatin and zeatin riboside production by mycorrhizal fungi in vitro (Barea and Azcon-Aguilar, 1982). 
Elevated cytokinin activity of seedlings inoculated with $G$. fasciculatum and $G$. mosseae was associated with concomitant improvements in total dry weight, phosphorus nutrition and vesicular-arbuscular mycorrhizal colonization. A minimum level of phosphorus nutrition is requisite for cytokinin activity. Significant improvements in the growth and phosphorus nutrition of other Citrus species due to vesicular-arbuscular mycorrhizal colonization have been reported (Menge et al., 1978). Cytokinins may facilitate phosphorus utilization and affect cell growth by attracting nutrients to developing tissue (Van Staden and Davey, 1979).

\section{References}

Allen M.F., Moore T.S. \& Christensen M. (1980) Phytohormone changes in Bouteloua gracilis infected by vesicular-arbuscular mycorrhizae. I. Cytokinin increases in host plant. Can J. Bot. 58, 271-274

Barea J.M. \& Az'con-Aguilar C. (1982) Production of plant growth regulating substances by the vesicular-arbuscular mycorrhizal fungus Glomus mosseae. Appl. Environ. Microbiol. 43, 810-813

Bethenfalvay G.L. \& Yoder J.F. (1981) The glycine-Glumus-rhizobium symbiosis. Physiol. Plant. 52, 141-14.5

Edriss M.H., Davis R.M. \& Burger D.W. (1984) Influence of mycorrhizal fungi on cytokinin production in sour orange. J. Am. Soc. Hortic. Sci. $109,587-590$

Horgan R. \& Kramers M.R. (1979) High performance liquid chromatography of cytokinins $J$. Chromatogr. 173, 263-270

Menge J.A., Labianauskas C.K., Johnson E.L.V. \& Platt R.G. (1978) Partial substitution of mycorrhizal fungi for phosphorus fertilization in the greenhouse culture of Citrus. Soil Sci. Am. J. 42, 926-930

Van Staden J. \& Davey J.E. (1979) The synthesis, transport, and metabolism of endogenous cytokinins. Plant Cell Environ. 2, 93-106 